\title{
The Effect of Leisure and Recreation on Sustainable Tourism: An Editorial Commentary
}

\author{
Tsung-Hung Lee *(D) and Fen-Hauh Jan \\ Graduate School of Leisure and Exercise Studies, National Yunlin University of Science and Technology, \\ Yunlin 640301, Taiwan; fenhauhjan@gmail.com \\ * Correspondence: thlee@yuntech.edu.tw
}

Citation: Lee, T.-H.; Jan, F.-H. The Effect of Leisure and Recreation on Sustainable Tourism: An Editorial Commentary. Sustainability 2022, 14, 54. https://doi.org/10.3390/ su14010054

Received: 14 December 2021 Accepted: 20 December 2021 Published: 21 December 2021

Publisher's Note: MDPI stays neutral with regard to jurisdictional claims in published maps and institutional affiliations.

Copyright: (C) 2021 by the authors. Licensee MDPI, Basel, Switzerland. This article is an open access article distributed under the terms and conditions of the Creative Commons Attribution (CC BY) license (https:// creativecommons.org/licenses/by/ $4.0 /)$.
This article aims to introduce a Special Issue that contains five chosen articles on sustainability. The issue of the environmental impact of tourism has become controversial, and sustainable tourism was proposed in the late 1980s [1]. The United Nations designated 2017 as the UN International Year of Sustainable Tourism for Development, and has declared the 2030 Agenda for Sustainable Development. The agenda implies the importance of sustainable tourism development [2]. Without this development, many destinations will face the destruction of ecological habitat and cultural resources, and there will be socio-cultural conflicts. Tourists will be dissatisfied and will no longer revisit the destinations.

The development of sustainable tourism assures steady local economic growth, poverty alleviation, and full and productive employment. In a social context, sustainability promises infrastructure building (e.g., roads, clean water, and food), the provision of public services, and women's empowerment. The development of sustainable tourism focuses on protecting and respecting biodiversity, using water and energy efficiently, and mitigating climate change. Sustainable tourism thus raises residents' standard of living and improves well-being. Accordingly, the development of sustainable tourism will guarantee win-win situations for environmental ecosystems, the inherence of socio-culture, residents well-being, and tourist satisfaction.

Tourism is regarded as a method of poverty alleviation, especially in less developed areas; however, tourism development is always accompanied by various negative impacts. Scholars classified these impacts into three categories: economic, socio-cultural, and environmental impacts. This is the so-called triple bottom line. Tourism brings job opportunities and other sources of revenue for local residents.

However, economic leakage, income inequality, and inflation may become economic costs for developing tourism. Tourism offers residents interaction with tourists, and it constructs tourism infrastructure, which also benefits locals. However, culture shock and contradictory behavior may confuse local residents' values. Tourist over-crowing may disturb residents' daily life. Although tourism development provides the chance to appreciate and plan local natural and cultural resources, tourist behavior may also destroy these resources. This may cause the destination to become less attractive than it once was.

Scholars have suggested tourism may promote or reduce residents' life satisfaction (e.g., health, safety, emotion, and material well-being). Additionally, from evidence of the residents' perceptions of sustainability, scholars have indicated that community-based tourism contributes to sustainable development [3]. Consequently, tourism can be regarded as a double-edged sword that brings considerable benefits and costs in terms of the economy, socio-culture, environment, and well-being. Thus, tourism planning and development needs to introduce the sustainable tourism concept to increase tourism benefits and reduce costs as much as possible.

Recently, new issues have arisen in the sustainable tourism context, such as the circular economy, climate change, environmental behavior, COVID-19, and sustainable indicators. Because of natural resource exhaustion and waste rising substantially, the circular economy has been intensively discussed worldwide. The term "circular economy" refers to limiting the use of resources and producing almost no waste, even if leftovers 
from production and consumption are recycled. The circular economy can be a part of slow tourism along with slow travel, slow food, and slow destinations. Slow tourism emphasizes walking or bicycling instead of using airplanes or cars, eating local food, staying longer in green Airbnbs, and appreciating local natural and cultural resources in more detail, which ultimately reduces $\mathrm{CO}_{2}$ emissions as much as possible to meet the goals of sustainable tourism [4].

As threats of climate change grow, reducing $\mathrm{CO}_{2}$ emissions is an urgent worldwide issue. Raising tourists' climate change acceptance will nurture tourists that practice an environmental attitude and behavior [5]. This will contribute to climate change mitigation. The tourist accommodations industry needs to limit use of water and energy, adopt renewable energy, and build infrastructures with eco-certified material. Moreover, eco-environmental innovations such as controlling pollution, using low-impact vehicles, saving energy and water, and preserving biodiversity are recommended [4].

Tourists' behavior and residents' attitudes are heavily debated in a sustainable tourism context. Some factors that influence tourists' environmental behavior include tourism image, cultural differences, environmental intervention, and interpretation service $[5,6]$. On the other hand, the tourist-resident relationship, emotional solidarity and subjective well-being, place attachment, perceived livelihood improvement, and empowerment may affect residents' attitudes in support of tourism $[7,8]$.

Recently, several interventions (e.g., social distancing, lockdowns, mask wearing, and vaccination policies) have tried to block the COVID-19 pandemic, which seriously affected the tourism industry. Most studies use protection motivation theory, risk perception theory, and the health belief model to examine tourists' behavior intentions [9]. Coping strategies and resilience systems may assure the destination's recovery [10].

The development of sustainability indicators of tourism destinations or tourism businesses is debated in assessing sustainable tourism [11,12]. Sustainable tourism indicators are holistic concepts that should include the perspectives of all stakeholders. Most researchers followed the concept of the triple bottom line (i.e., economic, socio-cultural, and environmental) to develop sustainable tourism indicators that evaluate the sustainability of tourism development $[11,12]$. From the residents' perspective, sustainable indicators may focus on contributions to the local residents, such as improving the local economy, encouraging good interrelationships with tourists and other residents, assuring natural and cultural resources, and promoting residents' well-being. From the destination managers' perspective, politics and technology also need to be included in the list of sustainable indicators. From tourism business owners' perspective, business performance will be a critical issue, with regard to factors such as financial, management, and marketing performance, efficient spending, tourists' satisfaction, tourism resources and equipment maintenance, and keeping a good relationship with internal (i.e., employees and stockholders) and external (i.e., government, local residents, tourists, and suppliers) stakeholders, which assure sustainably operating business. The sustainability indicators are helpful for tourism managers to evaluate and create strategies to assure the development of sustainable tourism [11,12].

Tourism market expansion is an important topic for tourism marketers, and the first paper in this Special Issue was contributed by Choi and Jang. They consider the friends and relatives of marriage immigrants as a new market. Choi and Jang used a qualitative approach to explore the possibility that marriage immigrant women could contribute to the sustainable development of the host country. Their findings suggested that leisure could benefit the marriage immigrant women's subjective well-being, and it could increase the social capital that significantly contributes to a sustainable society. The relatives and friends of immigrant women are regarded as information mediators who may contribute to the host country's reputation. By considering the travel and socially sustainable development in the present geographical areas, this paper contributes to the Southeast Asian market, which assists in the sustainable development of tourism destinations (Contributor 1).

In the context of aboriginal tourism, cultural authenticity is essential to cultural identity and sustainability [13]. Li and Zhou applied a mixed approach to Lacan's mirror stage 
theory to effectively develop a theoretical framework that assessed the authenticity of Naxi music in Lijiang, China. The framework evaluates the impact of local culture and various human activities that support local cultural sustainable development. The findings expand our knowledge of the theoretical and managerial implications of sustainable cultural tourism. This study not only applies to Naxi music but also to the assessment of similar performance-related tourism projects. It bridges the research gaps and extends the theoretical framework of intangible cultural heritage tourism (Contributor 2).

Chang, Hsu, and Chen identified the attributes and preferences of theme park tourists by using the choice experiment method. They explored tourists' willingness to pay using a random parameter logit model. They suggested tourist satisfaction and willingness to pay for a tourism experience are key issues for the sustainability of the business. They will also provide resilience for the business to recover from disasters (e.g., COVID-19). Tourism business managers need to identify the attributes of tourism products. They also need to be evaluated by tourists to determine tourists' willingness to pay, which allows managers to charge a reasonable price. In a theme park context, innovation of the entertainment facilities is vital for sustainable development. Thus, identifying tourists' preferences and willingness to pay can be regarded as a sustainable indicator that extends our knowledge and provides practical implications for creating sustainable tourism strategies (Contributor 3).

Tourists' on-site environmentally responsible behavior is essential for sustainable development at the destinations [5]. Kuo, Su, Wang, Kiatsakared, and Chen elucidated the theoretical framework of "place attachment-environmentally responsible behavior" and examined the mediating role of destination psychological ownership in their theoretical model. By first examining their theoretical model, this paper fills the research gap. This paper found that destination psychological ownership mediates place identity, place dependence, and tourists' environmentally responsible behavior. It therefore provides practical implications for managers to develop tourist destination psychological ownership. This paper thus extends our knowledge and contributes to the literature (Contributor 4).

Finally, hot spring tourism provides tourists with a multi-dimensional experience, which provides a sustainability approach towards environmental, socio-cultural, and economic values. Wang and Lin first attempted to test and validate a poverty alleviation theoretical framework based on the environmental, socio-cultural, and revisit intention dimensions of sustainability. Introducing sustainability concepts into hot spring experiences can effectively achieve SDG 1 and ultimately assist in sustainable hot spring tourism. Emphasizing the importance of a cultural landscape for sustainable tourism development and poverty alleviation, this paper highlights socio-cultural perspectives in the development of sustainable hot spring tourism and contributes to the literature (Contributor 5).

Overall, these five research articles demonstrate the effects of leisure and recreation on sustainable tourism, which could effectively elucidate sustainable tourism development by examining multiple tourism types and stakeholders. These articles may contribute to the research by providing references for theoretical and practical sustainable development.

\section{List of Contributions:}

1. Choi, S.H.; Jang, H. How can marriage immigrants contribute to the sustainability of the host country? Implications from the leisure and travel patterns of Vietnamese women in South Korea. Sustainability 2021, 13, 1039.

2. Li, D.; Zhou, S. Evaluating the authenticity of Naxi music in three stages from the perspective of Naxi musicians: An application of Lacan's mirror stage theory. Sustainability 2021, 13, 3720.

3. Kuo, H.M.; Su, J.Y.; Wang, C.H.; Kiatsakared, P.; Chen, K.Y. Place attachment and environmentally responsible behavior: The mediating role of destination psychological ownership. Sustainability 2021, 13, 6809.

4. Chang, M.Y.; Hsu, Y.S.; Chen, H.S. Choice experiment method for sustainable tourism in Theme Parks. Sustainability 2021, 13, 7146. 
5. Wang, W.C.; Lin, C.H. A Model for sustainable tourism development of hot spring destinations following poverty alleviation: Understanding the tourists' perspective. Sustainability 2021, 13, 9856.

Author Contributions: Conceptualization, T.-H.L.; writing-original draft preparation, F.-H.J.; writing - review and editing-T.-H.L.; supervision, T.-H.L. All authors have read and agreed to the published version of the manuscript.

Funding: This research received no specific grant from any funding agency in the public, commercial, or not-for-profit sectors.

Conflicts of Interest: The authors declare no conflict of interest.

\section{References}

1. World Commission on Environment and Development (WCED). Our Common Future; Oxford University Press: Oxford, UK, 1987.

2. United Nations General Assembly. Transforming Our World: The 2030 Agenda for Sustainable Development; Resolution 70/1, Doc ment A/RES/70/1, 17th Session Agenda Items 15 and 116, Adopted by the General Assembly on September 25th; United Nations: New York, NY, USA, 2015.

3. Lee, T.H.; Jan, F.H. Can community-based tourism contribute to sustainable development? Evidence from residents' perceptions of the sustainability. Tour. Manag. 2019, 70, 368-380. [CrossRef]

4. Sørensen, F.; Bærenholdt, J.O. Tourist practices in the circular economy. Ann. Tour. Res. 2020, 85, 103027. [CrossRef]

5. Ritchie, B.W.; Prideaux, B.; Thompson, M.; Demeter, C. Understanding Tourists' Attitudes toward Interventions for the Great Barrier Reef: An Extension of the Norm Activation Model. J. Sustain. Tour. 2021. [CrossRef]

6. Lee, T.H.; Jan, F.H.; Chen, J.C. Influence analysis of interpretation services on ecotourism behavior for wildlife tourists. J. Sustain. Tour. 2021. [CrossRef]

7. Munanura, I.E.; Needham, M.D.; Lindberg, K.; Kooistra, C.; Ghahramani, L. Support for tourism: The roles of attitudes, subjective wellbeing, and emotional solidarity. J. Sustain. Tour. 2021. [CrossRef]

8. Mody, M.; Woosnam, K.M.; Suess, C.; Dogru, T. Hapless victims or empowered citizens? Understanding residents' attitudes towards Airbnb using Weber's Theory of Rationality and Foucauldian concepts. J. Sustain. Tour. 2021. [CrossRef]

9. Kim, S.C.; Cooke, S.L. Using the health belief model to explore the impact of environmental empathy on behavioral intentions to protect ocean health. Environ. Behav. 2021, 53, 811-836. [CrossRef]

10. Kim, M.J.; Bonn, M.; Hall, C.M. Traveler biosecurity behavior during the COVID-19 pandemic: Effects of intervention, resilience, and sustainable development goals. J. Travel Res. 2021. [CrossRef]

11. Lee, T.H.; Hsieh, H.P. Indicators of sustainable tourism: A case study from a Taiwan's wetland. Ecol. Indic. 2016, 67, 779-787. [CrossRef]

12. Lee, T.H.; Jan, F.H.; Liu, J.T. Developing an indicator framework for assessing sustainable tourism: Evidence from a Taiwan ecological resort. Ecol. Indic. 2021, 125, 107596. [CrossRef]

13. Lee, T.H.; Lin, Y.H.; Wang, C.K. Can aboriginal images contribute to aboriginal cultural identity? Evidence from the perspective of tourists' images. Curr. Issues Tour. 2021. [CrossRef] 